\title{
Instantaneous formation of polyoxometalate-based cerium vanadium oxide gels
}

Received 00th January 20xx, Accepted 00th January 20xx

DOI: $10.1039 / x 0 x \times 00000 x$

www.rsc.org/

\begin{abstract}
Andrey Seliverstov ${ }^{a}$, Mojca Rangus ${ }^{b}$, Martin Hartmann ${ }^{b}$, Scott G. Mitchell ${ }^{c}$, and Carsten Streb ${ }^{a^{*}}$
The instantaneous formation of mechanically stable vanadium oxide gels starting from souble polyoxovanadates is reported together with initial application studies. Upon addition of phosphoric acid to solutions containing a vanadium oxide source (e.g. $\left.\left(n \mathrm{Bu}_{4} \mathrm{~N}\right)_{4}\left[\mathrm{~V}_{4} \mathrm{O}_{12}\right]\right)$ and $\mathrm{Ce}^{3+}$, instantaneous formation (reaction time $<1 \mathrm{~s}$ ) of a vanadium oxide gel is observed. The gel shows unique mechanical and thermal stability (up to $\sim 180^{\circ} \mathrm{C}$ ). High permeability of the gel is observed, allowing its use for long-term acid delivery into aqueous media or for the adsorption of organic aromatic dye pollutants from solution. A range of spectroscopic and electron microscopic techniques provide insight into the gel formation and the gel composition: an intertwined 3D matrix of vanadium oxide nanowires $(d \sim 10 \mathrm{~nm})$ is identified as inorganic matrix which enables formation of the mechanically stable gel.
\end{abstract}

\section{Introduction}

Polyoxometalates (POMs) are the molecular analogues of solid-state metal oxides. ${ }^{1}$ They have attracted vast interest in academia and industry due to their widespread applications in (photo)-catalysis, ${ }^{2,3}$ energy storage, ${ }^{4,5}$ molecular electronics ${ }^{6}$ and nanomaterials science. ${ }^{7}$ POMs can be employed under homogeneous or heterogeneous conditions. While the use of POMs under homogeneous conditions provides detailed insight into reactivity and solution behaviour, many technological applications rely on heterogeneous systems, e.g. for facile separation and recycling. ${ }^{8}$ The need to embed POMs in heterogeneous systems has been recognized and various routes for POM heterogenization have been reported. ${ }^{9}$ One promising approach is the use of POMs as precursors for the formation of metal oxide gels. This approach allows the tuning of POM precursor properties on the molecular level; further fine-tuning of the materials properties is possible by incorporation of additional reactive components. POM-based gels with unique optical, ${ }^{10}$ electrochemical ${ }^{11,12}$ and thermo/photoresponsive behaviour ${ }^{13}$ have been developed. Polyoxovanadates are particularly attractive precursors for gel formation as their conversion into nanostructured vanadium oxide gels is well-known. ${ }^{14}$ Vanadium oxide gels are technologically highly relevant materials ${ }^{15}$ and their use in solar energy conversion, ${ }^{16,17}$ (bio)sensors, ${ }^{18,19}$ porous materials ${ }^{20,21}$ and battery electrodes ${ }^{22,23}$ has been reported.

\footnotetext{
a. Institute of Inorganic Chemistry I, Ulm University, Albert-Einstein-Allee 11, 89081 Ulm, Germany, carsten.streb@uni-ulm.de; www.strebgroup.net.

${ }^{b .}$ Erlangen Catalysis Resource Center ECRC, Friedrich-Alexander-Universität Erlangen-Nürnberg, Egerlandstr. 3, 91058 Erlangen, Germany.

Instituto de Ciencia de Materiales de Aragón (ICMA-CSIC), Universidad de Zaragoza, 50019-Zaragoza, Spain

Electronic Supplementary Information (ESI) available: Synthetic and analytical details are provided. See DOI: $10.1039 / x 0 x \times 00000 x$
}

\section{Results and discussion}

Gel synthesis
Here, we report a novel synthetic route which enables the instantaneous formation of a cerium vanadium-oxide based organogel. The gel is formed spontaneously when a basic organic solution containing a vanadate precursor (e.g. $\left.\left(n \mathrm{Bu}_{4} \mathrm{~N}\right)_{3}\left[\mathrm{H}_{3} \mathrm{~V}_{10} \mathrm{O}_{28}\right]\right)$ and $\mathrm{Ce}^{3+}$ is acidified using aqueous phosphoric acid (Fig. 1). Gelation occurs instantaneously $\left(t_{\text {gelation }}<1 \mathrm{~s}\right)$ and a mechanically stable gel which can be cast into a desired shape (disk, cylinder, etc.) and manipulated using tweezers is formed. The high mechanical stability of the gel is shown, as the gel is self-supporting and can be cast or cut into the required shape (Fig. 1).

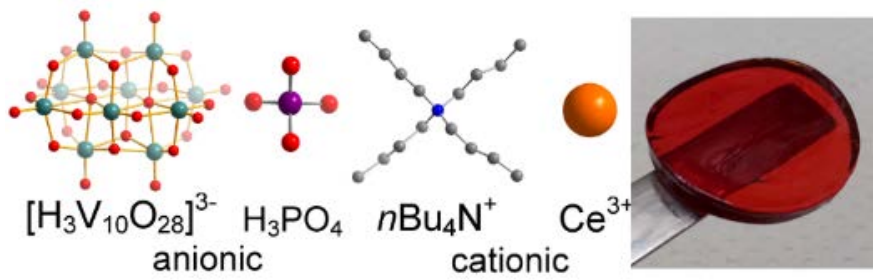

Figure 1: Left: Components required for gel formation: a vanadium oxide source, typically a polyoxovanadate e.g. $\left(n \mathrm{Bu}_{4} \mathrm{~N}\right)_{3}\left[\mathrm{H}_{3} \mathrm{~V}_{10} \mathrm{O}_{28}\right]$ is dissolved in basic $\left(\left(n \mathrm{Bu}_{4} \mathrm{~N}\right)_{3} \mathrm{OH}-\right.$ containing) organic solution (e.g. DMSO) and acidified using phosphoric acid in the presence of $\mathrm{Ce}^{3+}$ cations. Instantaneous gelation is observed. Right: photograph of a typical free-standing gel sample.

The formation of the gel was discovered by serendipity when we investigated the synthesis of lanthanide-functionalized polyoxovanadate clusters in organic solution. ${ }^{24,25}$ It was observed that when a basic DMSO solution containing $n \mathrm{Bu}_{4} \mathrm{NOH},\left(n \mathrm{Bu}_{4} \mathrm{~N}\right)_{3}\left[\mathrm{H}_{3} \mathrm{~V}_{10} \mathrm{O}_{28}\right]$ and $\mathrm{Ce}\left(\mathrm{NO}_{3}\right)_{3} \times 6 \mathrm{H}_{2} \mathrm{O}$ is acidified with aqueous phosphoric acid, the solution viscosity instantaneously increases and a mechanically stable gel is obtained. Systematic analysis of the reaction parameters showed that both, $\mathrm{Ce}^{3+}$ and phosphoric acid are required for gel formation. Attempts to replace $\mathrm{Ce}^{3+}$ with a wide range of other metal cations, including lanthanides, alkali and alkali earth metals did not result in the formation of a gel. Gelation is therefore specific to $\mathrm{Ce}^{3+}$. While the exact role of $\mathrm{Ce}^{3+}$ is still unclear, we suggest that $\mathrm{Ce}^{3+}$ acts as ionic cross-linker between the building blocks of the gel. ${ }^{26}$ Attempts to replace phosphoric acid with other mineral or organic acids $\left(\mathrm{HCl}_{\mathrm{aq}}\right.$, $\mathrm{HNO}_{3}, \mathrm{H}_{2} \mathrm{SO}_{4}$, acetic acid, benzoic acid) did not result in 
gelation, indicating that phosphate anions are also critical for the gel formation. In contrast, the vanadium oxide source can be varied and gel formation is possible with a range of soluble vanadium oxide precursors such as $\left(n \mathrm{Bu}_{4} \mathrm{~N}\right)_{4}\left[\mathrm{~V}_{4} \mathrm{O}_{12}\right]$, $\left(n \mathrm{Bu}_{4} \mathrm{~N}\right)_{3}\left[\mathrm{H}_{3} \mathrm{~V}_{10} \mathrm{O}_{28}\right]$ or hydrolysed $\mathrm{V}_{2} \mathrm{O}_{5}$. As the synthesis is carried out under basic conditions (i.e. in the presence of $n \mathrm{Bu}_{4} \mathrm{NOH}$ ), the compounds are converted into metavanadatetype precursors, ${ }^{27-29}$ thus explaining their similar gel-forming reactivities upon acidification. For reasons of brevity, this report is focused on gels based on $\left(n \mathrm{Bu}_{4} \mathrm{~N}\right)_{3}\left[\mathrm{H}_{3} \mathrm{~V}_{10} \mathrm{O}_{28}\right]$.

It was further demonstrated, that gel formation is achieved in a range of polar organic solvents e.g. dimethyl sulfoxide (DMSO) or $\mathrm{N}, \mathrm{N}^{\prime}$-dimethyl formamide (DMF), giving access to a vanadium oxide organogels and hydrogels, However, lower mechanical stability was observed for the hydrogel compared with the respective organogels, therefore this report is focused on DMSO-based gels. ${ }^{\ddagger}$

\section{Gel characterization}

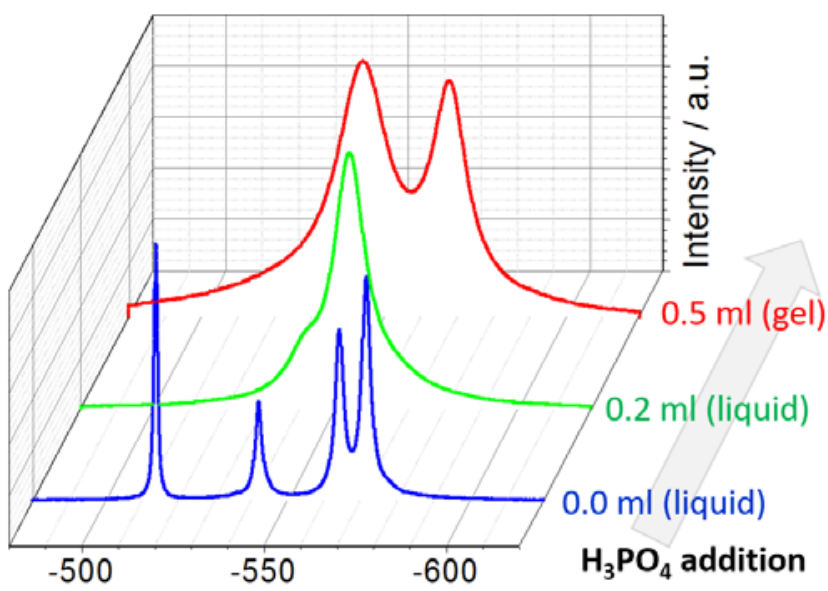

${ }^{51}$ V-NMR Chemical Shift $\delta / \mathrm{ppm}$

Figure 2: ${ }^{51} \mathrm{~V}$-NMR data showing the changes in chemical shifts observed for the vanadium centers during gel formation. Conditions: solvent: DMSO; precursor: $\left(n \mathrm{Bu}_{4} \mathrm{~N}\right)_{3}\left[\mathrm{H}_{3} \mathrm{~V}_{10} \mathrm{O}_{28}\right]$ hydrolyzed by addition of $n \mathrm{Bu}_{4} \mathrm{NOH} . \mathrm{H}_{3} \mathrm{PO}_{4}(9 \mathrm{M})$.

${ }^{51}$ V-NMR-spectroscopy: Investigation of the gelation processes is non-trivial, particularly if multi-component systems are present. We have used ${ }^{51} \mathrm{~V}$-NMR spectroscopy to investigate the gelation process. To this end samples of the precursor solution containing $\left(n \mathrm{Bu}_{4} \mathrm{~N}\right)_{3}\left[\mathrm{H}_{3} \mathrm{~V}_{10} \mathrm{O}_{28}\right]$ in $\mathrm{DMSO} / n \mathrm{Bu}_{4} \mathrm{NOH}$ and solutions/gels formed at increasing $\mathrm{H}_{3} \mathrm{PO}_{4}$ concentration (i.e. acidic $\mathrm{pH}$ ) were examined. The data (Fig. 2) show significant changes of the chemical shifts upon gelation: ${ }^{51} \mathrm{~V}-\mathrm{NMR}$ data shows that the basic precursor solution $\left(\left(n \mathrm{Bu}_{4} \mathrm{~N}\right)_{3}\left[\mathrm{H}_{3} \mathrm{~V}_{10} \mathrm{O}_{28}\right]\right.$ in $\mathrm{DMSO} / n \mathrm{Bu}_{4} \mathrm{NOH}$ ) contains several small vanadate species as observed by four distinct signals in the range of $\delta=-500$ to $600 \mathrm{ppm}$, corresponding to mononuclear orthovanadate species $\left[\mathrm{VO}_{4}\right]^{3-}(\delta=-542 \mathrm{ppm}),\left[\mathrm{HVO}_{4}\right]^{2-}(\delta=-564 \mathrm{ppm})$ and $\left[\mathrm{H}_{2} \mathrm{VO}_{4}\right]^{-}(\delta=-571 \mathrm{ppm})$ as well as oligomeric "metavanadate"related species, e.g. $\left[\mathrm{V}_{3} \mathrm{O}_{10}\right]^{5-}(\delta=-514 \mathrm{ppm}){ }^{30}$

Upon $\mathrm{H}_{3} \mathrm{PO}_{4}$ addition (but still in the non-gelled form), one major signal arises at $\delta=-554 \mathrm{ppm}$ (assigned to dinuclear $\left[\mathrm{V}_{2} \mathrm{O}_{7}\right]^{4-}$ species) $)^{30}$, while the resonance at $\delta=-542 \mathrm{ppm}$ can be assigned to residual $\left[\mathrm{VO}_{4}\right]^{3-} \cdot{ }^{30}$ The data therefore suggest that the initial steps of acid-induced vanadium oxide polycondensation are observed. Upon gelation, two distinct signals are observed by ${ }^{51} \mathrm{~V}-\mathrm{NMR}$ spectroscopy at $\delta=-568 \mathrm{ppm}$ and $\delta$ $=-544 \mathrm{ppm}$, indicating that two vanadate coordination environments are present within the gel structure. The chemical shifts observed are in line with tetrahedrally coordinated vanadate centres in an all-oxo environment. ${ }^{30}$ Note that other possible vanadium coordination geometries lead to significant shifts of the ${ }^{51} \mathrm{~V}$-NMR signals: square pyramidal $\left[\mathrm{VO}_{5}\right]$ units in solid-state vanadium oxide gels are observed at $\delta c a .280 \mathrm{ppm},{ }^{15}$ while octahedral $\left[\mathrm{VO}_{6}\right]$ units are observed at $\delta \mathrm{ca}$. 400-500 ppm (e.g. in $\left[\mathrm{V}_{10} \mathrm{O}_{28}\right]^{6-}$ ). ${ }^{30}$

Electron microscopy: The micro- and nanostructure of the gel was examined using scanning electron microscopy (SEM) and transmission electron microscopy (TEM) and high-angle annular dark field-scanning transmission electron microscopy (HAADF-STEM). SEM imaging of the semi-dried gel shows a smooth surface (Fig. 3a and b). More detailed TEM (Fig. 3c and d) and HAADF-STEM analysis (Fig. S7) revealed that the gel was stabilized by a vast network of intertwined fibrillary structures. The fibres observed feature large aspect ratios and typical diameters $<10 \mathrm{~nm}$ are observed (Fig. $3 \mathrm{c}$ and d). Based on previous findings, ${ }^{15,31}$ these structures are assigned as vanadium oxide fibres which is further supported by the ${ }^{51} \mathrm{~V}$ NMR data and also FT-IR data which show distinct V-O vibrational modes within the gel (Fig. S1). EDS analysis showed that these fibular structural features contain large amounts of vanadium together with smaller amounts of phosphate and cerium (Fig. S8). The presence of vanadium was detected by their characteristic X-ray emission signals at 4.95 and $0.51 \mathrm{eV}$ ( $\mathrm{K}_{\alpha}$ and $\mathrm{L}_{\alpha}$, respectively). The $\mathrm{Ce} \mathrm{L}_{\alpha}$ signal was observed at 4.84 $\mathrm{eV}$ (overlaid with the $\mathrm{V}$ signal at $4.95 \mathrm{eV}$ ), while the $\mathrm{M}$ emission can be detected at $0.88 \mathrm{eV}$ (a purely Ce-based signal) (Fig. S8b). See ESI for further details.
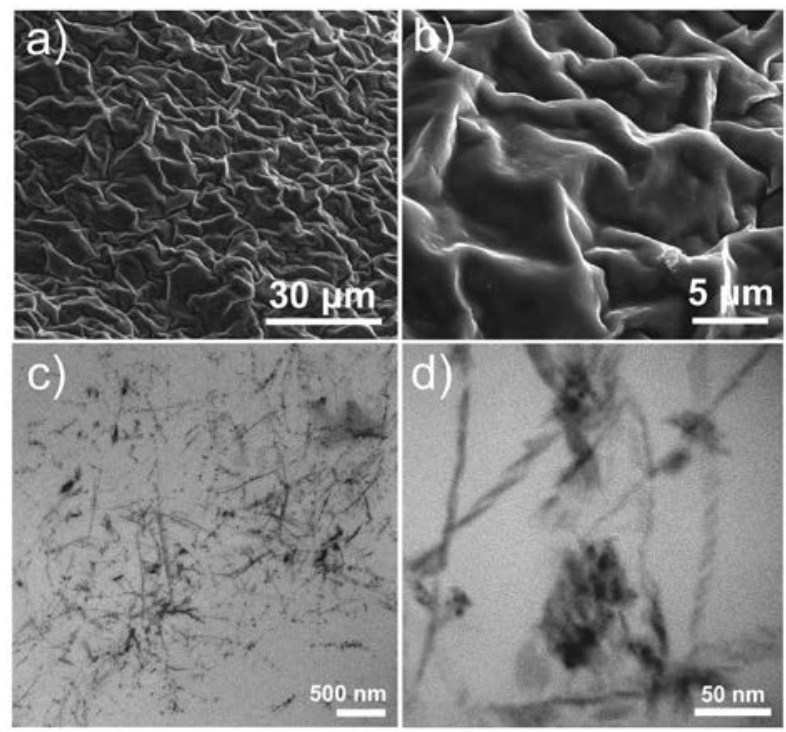

Figure 3: Electron microscopic characterization of the gel. Top (a-b): Scanning electron microscopy (SEM) images showing the smooth gel surface. Bottom (c-d): transmission electron microscopy (TEM) images showing the internal network of vanadium oxide fibres stabilizing the gel matrix. 


\section{Gel properties and applications}

Thermal stability: initial observations showed that the gels possess a high thermal stability and do not feature a degelation temperature where the system obtains enough thermal energy to overcome the gel-forming interactions. This corroborates our observation that the gel is stabilized by an internal network of intertwined vanadium oxide fibres which are thermally stable and do not allow reversible de-gelation by temperature increase. When the gel reaches the boiling-point of the corresponding solvent (e.g. DMSO: $T_{\text {evaporation }}=189{ }^{\circ} \mathrm{C}$ ), irreversible thermal decomposition of the gel is observed due to solvent-loss. Below the given decomposition temperature, the gel is not irreversibly changed: for the DMSO-based gel, loss of solvent ( $<5$ wt.-\%) is observed upon prolonged heating $(24 \mathrm{~h})$ to $100{ }^{\circ} \mathrm{C}$. Solvent loss leads to a reversible shrinking of the gel: immersion of the de-solvated gel into DMSO results in a re-uptake of solvent to reconstitute the original gel shape.

Chemical stability: the stability of the gel against high ionic strength solutions (aqueous, $1 \mathrm{M} \mathrm{NaCl}$ solution) was investigated by immersing pre-formed gel cylinders $(I=1.0 \mathrm{~cm}$, $d=0.85 \mathrm{~cm}$ ) into the salt solution for $24 \mathrm{~h}$. No degradation or loss of shape or mechanical stability of the gel was observed, highlighting the stable internal support structure. Similar experiments were conducted using a range of organic lowpolarity solvents such as hexane, diethyl ether, ethyl acetate, toluene and no gel degradation was observed, further illustrating the stable network present within the gel.

Pollutant removal: It was hypothesized that the accessible internal structure of the gels might make them useful as solid adsorbents for the uptake of organic pollutants from aqueous solution. As a model pollutant the azo-dye basic blue 41 (BB41) was used. ${ }^{32}$ In a typical experiment, a cylindrical piece of gel (diameter $0.85 \mathrm{~cm}$, height $1.0 \mathrm{~cm}$, surface area: $3.8 \mathrm{~cm}^{2}$, volume: $0.56 \mathrm{~cm}^{3}$ ) was exposed to an aqueous solution of BB41 $([\mathrm{BB} 41]=12 \mathrm{mM})$ and the solution was left to equilibrate. The dye uptake kinetics were followed UV-Visspectrometrically and pseudo first-order uptake kinetics were observed and dye absorption reached a steady state after ca. $96 \mathrm{~h}$ (Fig. 4) with a maximum dye removal from solution of $\sim 87$ $\%$. The dye-loaded gel was still mechanically stable and was removed from solution using tweezers.

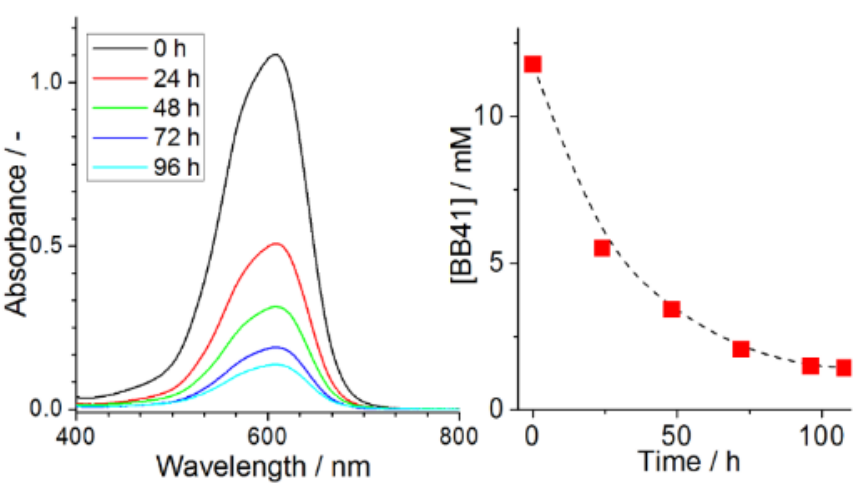

Figure 4: Removal of the organic model pollutant BB41 from aqueous solution by the vanadium oxide gel. Conditions: $V=3.0 \mathrm{ml},[\mathrm{BB} 41]_{0}=12 \mathrm{mM}$; gel surface area: $3.5 \mathrm{~cm}^{2}$, gel volume: $0.5 \mathrm{~cm}^{3}$.

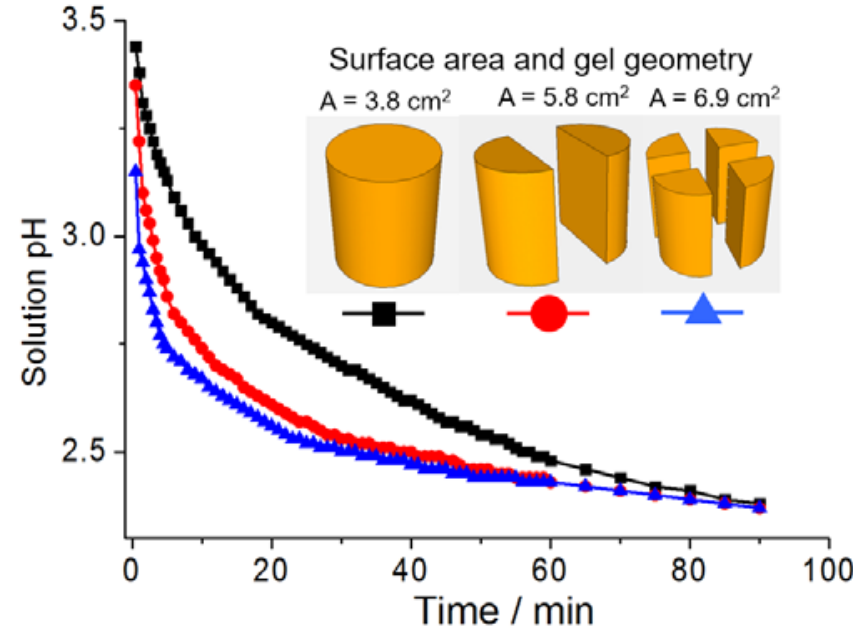

Figure 5: Surface-are dependent acid release of gel samples into aqueous solution $(\mathrm{V}=3.0 \mathrm{ml})$, highlighting that the gel can be used for continuous longterm acid release. The release rate can be controlled by the surface area of the gel. Gel geometries and surface areas A used for release are shown as inset.

Acid release: Due to the synthetic procedure it was noted that the POM-gels are acidic in nature and it was suggested that the gels could be used for the slow release of $\mathrm{H}_{3} \mathrm{O}^{+}$into solution. This was exemplified by exposing a piece of the DMSO-based gel cylinder (diameter $0.85 \mathrm{~cm}$, height $1.0 \mathrm{~cm}$, surface area: $3.8 \mathrm{~cm}^{2}$, volume: $0.56 \mathrm{~cm}^{3}$ ) to an aqueous solution ( $V=3.0 \mathrm{ml}$, initial $\mathrm{pH} 3.5$, Fig. 5 ). The solution $\mathrm{pH}$ was reduced in an exponential fashion and equilibrium was reached after $90 \mathrm{~min}$, resulting in a final solution $\mathrm{pH}$ of 2.4 . After the $\mathrm{H}_{3} \mathrm{O}^{+}$release, the gel remains unchanged and can be separated from the solution using tweezers. The gel can be recharged with acid by immersion in a DMSO-solution containing $\mathrm{H}_{3} \mathrm{PO}_{4}$ and can be re-used for a second acid release run in water (ESI). It was further demonstrated that the $\mathrm{H}_{3} \mathrm{O}^{+}$release can be modulated by varying the accessible surface area of the gel. To this end, the original gel cylinders were cut in half or quarters using a scalpel, resulting in increased surface areas. Acid release into solution increased with increasing surface area, see Fig. 5. The results show that the gel can be used as a solid source of protons which are released into solution with over a prolonged period of time, making it an interesting candidate for the study of slow, proton-dependent reactions.

\section{Conclusions}

In summary, we report a facile route which allows the instantaneous formation of mechanically stable cerium vanadium oxide gels. Material characterization provides insight into the gel structure and it is shown that the gel is stabilized by intertwined vanadium oxide nanofibers $(\mathrm{d} \sim 10 \mathrm{~nm}$ ). Initial reactivity studies show that the gel features unprecedented thermal stability, does not de-gelate upon heating, can deliver protons into aqueous solution and shows promising pollutant adsorption properties from aqueous solution. Future studies will further explore the molecular-level structure of the gel and aim at further analysis of the adsorbent properties of the gel. 


\section{Acknowledgements}

Financial support by the Deutscher Akademischer Austauschdienst (DAAD) EU COST Action CM1203, Ulm University, Friedrich-Alexander-Universität Erlangen-Nürnberg and Fundación General CSIC (Programa Comfuturo) is gratefully acknowledged. The authors would like to acknowledge the use of The Advanced Microscopy Laboratory (LMA-INA).

\section{Notes and references}

¥ The gels employed for the application studies, were prepared as follows: to a solution of $\left(n \mathrm{Bu}_{4} \mathrm{~N}\right)_{3}\left[\mathrm{H}_{3} \mathrm{~V}_{10} \mathrm{O}_{28}\right](0.06 \mathrm{mmol})$ and $\mathrm{CeCl}_{3} \times 7 \mathrm{H}_{2} \mathrm{O}(0.11 \mathrm{mmol})$ in DMSO $(5 \mathrm{ml})$ was added a methanolic solution of TBAOH $(1.5 \mathrm{M}, 0.3 \mathrm{ml})$ at $80{ }^{\circ} \mathrm{C}$. The solution was stirred for $5 \mathrm{~min}$ and $\mathrm{H}_{3} \mathrm{PO}_{4}(9 \mathrm{M}, 0.45 \mathrm{ml})$ was added, resulting in the instantaneous formation of the gel which could be mechanically removed from the reaction vessel and cut into the desired shape using a scalpel.

L. Cronin, A. Müller and (guest eds.), Chem. Soc. Rev., 2012, 41, 7325-7648.

C. L. Hill, J. Mol. Catal. A Chem., 2007, 262, 2-6.

C. Streb, Dalt. Trans., 2012, 41, 1651.

A. Sartorel, M. Bonchio, S. Campagna and F. Scandola, Chem. Soc. Rev., 2013, 42, 2262-2280. Y. C. Ji, L. J. Huang, J. Hu, C. Streb and Y.-F. F. Song, Energy Environ. Sci., 2015, 8, 776-789.

6 J. Lehmann, A. Gaita-Arino, E. Coronado and D. Loss, Nat. Nanotechnol., 2007, 2, 312-317.

7 D. L. Long, R. Tsunashima and L. Cronin, Angew. ChemieInternational Ed., 2010, 49, 1736-1758. Y. Leng, J. Wang, D. Zhu, X. Ren, H. Ge and L. Shen, Angew. Chemie, 2009, 121, 174-177. S. Suib, Ed., New and Future Developments in Catalysis: Hybrid materials, Composites and Organocatalysts, Elsevier, Amsterdam, 2013. S. Favette, B. Hasenknopf, J. Vaissermann, P. Gouzerh and C. Roux, Chem. Commun. (Camb)., 2003, 2664-2665. X. Tong and V. Thangadurai, J. Phys. Chem. C, 2015, 119, 7621-7630. R. Tsunashima, C. Richmond and L. Cronin, Chem. Sci., 2012, 3, 343. P. He, B. Xu, H. Liu, S. He, F. Saleem and X. Wang, Sci. Rep., 2013, 3, 1833.

14 J. Livage, Coord. Chem. Rev., 1998, 178-180, P, 999-1018.

15 J. Livage, Chem. Mater., 1991, 3, 578-593.

16 O. Dvorak and M. K. De Armond, Chem. Mater., 1992, 4, 1074-1077.

17 K. Zilberberg, S. Trost, J. Meyer, A. Kahn, A. Behrendt, D. Lützenkirchen-Hecht, R. Frahm and T. Riedl, Adv. Funct. Mater., 2011, 21, 4776-4783.

18 J. Liu, X. Wang, Q. Peng and Y. Li, Adv. Mater., 2005, 17, 764-767.

19 V. Glezer and O. Lev, J. Am. Chem. Soc., 1993, 115, 25332534.

20 G. T. Chandrappa, N. Steunou and J. Livage, Nature, 2002,
21

416, 702.

O. Durupthy, M. Jaber, N. Steunou, J. Maquet, G. T. Chandrappa and J. Livage, Chem. Mater., 2005, 17, 63956402.

N. A. Chernova, M. Roppolo, A. C. Dillon and M. S. Whittingham, J. Mater. Chem., 2009, 19, 2526-2552. G. Li, S. Pang, L. Jiang, Z. Guo and Z. Zhang, J. Phys. Chem. $B, 2006,110,9383-9386$.

A. Seliverstov and C. Streb, Chem. - A Eur. J., 2014, 20, 9733-9738.

A. Seliverstov and C. Streb, Chem. Commun., 2014, 50, 1827-1829.

Y. Zhang, N. Zhou, S. Akella, Y. Kuang, D. Kim, A. Schwartz, M. Bezpalko, B. M. Foxman, S. Fraden, I. R. Epstein and B. Xu, Angew. Chemie Int. Ed., 2013, 52, 11494-11498. J. Tucher, L. C. Nye, I. Ivanovic-Burmazovic, A. Notarnicola and C. Streb, Chem. - A Eur. J., 2012, 18, 10949-10953. J. Forster, B. Rösner, R. H. Fink, L. C. Nye, I. IvanovicBurmazovic, K. Kastner, J. Tucher and C. Streb, Chem. Sci., 2013, 4, 418-424.

K. Kastner, J. T. Margraf, T. Clark and C. Streb, Chem. - A Eur. J., 2014, 20, 12269-12273.

D. Rehder, Bull. Magn. Reson., 1982, 4, 33-83.

C. Streb, R. Tsunashima, D. a. MacLaren, T. Mcglone, T. Akutagawa, T. Nakamura, A. Scandurra, B. Pignataro, N. Gadegaard and L. Cronin, Angew. Chemie-International Ed., 2009, 48, 6490-6493. 